\title{
Os elos entre memória e teatro: a recepção da performance e o grupo giz-en-scène
}

\section{The links between memory and theater: the performance reception and the giz-en-scène group}

\section{Marco Aurélio Rodrigues ${ }^{1}$}

Resumo: O presente trabalho aborda três elementos da teoria da Recepção da Performance (HALL; HARROP, 2010), mimese, memória e psique, para discutir algumas evidências nas apresentações do grupo teatral Giz-en-Scène e a importância que os processos mnemônicos têm, há séculos, enquanto partes constitutivas da arte dramática.

Palavras-chave: memória; teatro; Giz-en-Scène.

Abstract: The present paper addresses three elements of the Performance Reception theory (HALL; HARROP, 2010), mimesis, memory and psyche, to discuss some evidence in the presentations of the theater group Giz-en-Scène and the importance that mnemonic processes have, for centuries, as constitutive parts of dramatic art.

Keywords: memory; theatre; Giz-en-Scène.

Desde a Antiguidade, os gregos já lidavam com a ideia de que a memória pertencia a um universo de extrema importância para o ser humano. Hesíodo, por exemplo, na Teogonia, escrita, possivelmente, entre 760 e 600 a.C. ${ }^{2}$, atrelou, na construção da cosmogonia helênica, a figura da

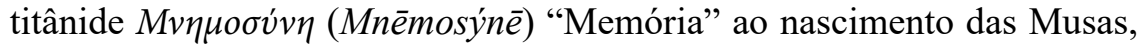
ou seja, a deusa estaria intimamente vinculada às divindades responsáveis

\footnotetext{
1 Prof. Dr. Marco Aurélio Rodrigues Estudos Clássicos Letras-Português (UNIFAP-Santana).

2 Tal data é sugerida por Schlegel e Weinfield (2006, p. 10).
} 
pelas finas artes compostas pelo homem, como o teatro, a pintura, a ciência etc. A esse respeito, ressalta Torrano (1995, p. 22):

As Musas têm e mantêm o domínio da revelação (ser) e do esquecimento (não-ser) e este domínio é o da raiz originante de todo poder e exercício de poder. $\mathrm{Na}$ expressão mítica de Hesíodo isto se diz: as Musas são filhas de Memória e de Zeus.

Nesse sentido, filhas da Memória e do todo-poderoso olímpico, Zeus, as Musas dominam aspectos de influência extremamente importante para a existência humana, o "ser" e o "não-ser", traços constituintes da identidade do mortal. Não é para menos que, em 472 a.C., a questão da memória tenha sido significativa no cuidado de Ésquilo para a composição de Persas, a mais antiga tragédia remanescente do período clássico cujo mote se centra em um fato histórico: os momentos finais das Guerras Médicas.

Anos antes da apresentação de Ésquilo, o tragediógrafo Frínico teria sido multado e proibido de representar novamente um drama denominado Queda de Mileto ${ }^{3}$, o que faria qualquer autor ficar receoso por se amparar em um relato histórico que pudesse causar qualquer identificação para o público. No entanto, Ésquilo demonstra todo seu potencial e conhecimento em relação ao mito, fato este que lhe possibilita desconstruir a realidade com aspectos que distanciam o espectador da memória afetiva em relação à guerra recente. Assim, o intervalo espaço-temporal, a riqueza de detalhes imagéticos, a interpretação simbólica e universalista ligada aos fatos, aspectos do maravilhoso em relação à corte persa, como a presença do espectro do rei Dario, todos esses elementos levaram a audiência a um outro patamar, a redescobrir suas lembranças e a concebê-las por meio de

3 A esse respeito, Loraux (2002, p. 43) sintetiza os acontecimentos, questionando justamente o poder da memória no espaço teatral. 
uma narrativa fantástica e gloriosa.

Ao discorrer sobre memória e tragédia, Favorini (2009, p. 49) tece algumas considerações sobre Ésquilo e Frínico:

The Persians (472 BCE) was one of a trio of Persian War plays engaging events within the vividly living memory of its hearers. Preceding Aeschylus' play by twenty years was Phrynichus' The Capture of Miletus, produced scarcely more than half a century after the putative invention of the drama by Thespis. Almost all of what we know of this lost play derives from Herodotus, who was writing sixty to seventy years after the play's likely date of production. In Book VI, chapter 21 of what different translators term "The History," "Histories," or "Researches," Herodotus preserves an anecdote of the succès de scandale surrounding what may have been the first of actual drama of the Western tradition, wrought from the too-fresh horrors of the Persian War. ${ }^{4}$

O curioso, nas palavras de Favorini, reside no fato de o autor ressaltar a questão do espaço temporal que separa Téspis de Frínico, Frínico de Ésquilo e, por sua vez, Heródoto de todos esses dramaturgos. Tal marca reforça, também, a importância de uma relação muito sofisticada com a memória, que, no período, tinha papel crucial no relato e na documentação dos eventos.

Sendo assim, desde os primórdios, o processo mnemônico ligado ao impacto presente nas representações, tanto por sua carga significativa

4 Os Persas (472 a.C.) fizeram parte de uma tríade de peças da Guerra Pérsica envolvendo eventos vivamente presentes na memória de seus ouvintes. Precedendo a peça de Ésquilo por vinte anos, estava A Queda de Mileto, de Frínico, produzida apenas pouco mais de meio século após a suposta invenção do drama por Téspis. Quase tudo o que sabemos sobre essa peça perdida deriva de Heródoto, que estava escrevendo sessenta a setenta anos após a provável data de produção da peça. No livro VI, capítulo 21, do que diferentes tradutores denominam "A História", "Histórias" ou "Pesquisas", Heródoto preserva uma anedota dos succès de scandale em torno do que pode ter sido o primeiro drama real da tradição ocidental, forjado dos horrores muito recentes da Guerra Pérsica. (Traduções de minha lavra) 
posterior à apresentação, como as lembranças que os espectadores carregam para o teatro, já eram motivos de reflexão do homem e permanecem intrínsecos à construção da performance dramática. Se por um lado, a memória poderia ser um fato de recordação histórica, por outro, como pontua Segal (2001, p. 35), em Bacantes, de Eurípides, tem-se um exemplo claro de que o mote mítico também se apropriava das questões que envolviam a memória e faziam parte da elaboração da trama teatral. Embora o estudioso estivesse discutindo a controversa passagem conhecida como Composito Membrorum (2001, p. 27), ele ressalta a ideia de que Eurípides lidou com personagens que precisavam rememorar sua condição, numa espécie de "reconhecimento dionisíaco". Favorini (2009, p. 29), ao tecer um comentário sobre a explicação de Segal, acrescenta:

[...] Agave's recognition is embodied and communal, as signaled by the Compositio Membrorum. Even so, in re-membering her son, one of the philoi from whom she takes her being, she is tragically remembering herself. It would be much better if she were able to dissociate herself from her crime, to claim that she is not the person who killed her son-in the manner of what is now called identity dissociation disorder (formerly "multiple personalities"). But she cannot. Who she was, who she is, and who she will be are one. She is returned to herself at the very moment of severing herself from loved ones-a movement that links the most ancient drama we have to late-modernist memory plays like Paula Vogel's How I Learned to Drive and Hélène Cixous' Dora, wherein the delayed recognition that Freud would later call Nachträglichkeit (referring to the postprocessing of a trauma or memory) figures prominently. ${ }^{5}$

5 [...] o reconhecimento de Agave é corporificado e comunitário, como sinalizado pelo Compositio Membrorum. Mesmo assim, ao relembrar o filho, um dos philoi de quem ela parte, ela se lembra tragicamente de si mesma. Seria muito melhor se ela fosse capaz de se dissociar de seu crime, alegar que ela não é a pessoa que matou seu filho - do modo como agora se denomina de distúrbio de dissociação de identidade (anteriormente "personalidades múltiplas"). Mas ela não pode. Quem ela era, quem ela é e quem ela será são uma delas. Ela volta a si mesma no exato momento em que se afasta dos entes queridos - um movimento que liga o 
Assim, tanto a tragédia quanto a comédia oferecem elementos que, externos ou inseridos na própria trama, estimulam a memória enquanto aspecto constitutivo do ser humano e de sua experiência de vida. Nesse sentido, o exercício mnemônico se torna, no âmbito das análises dramáticas, um componente imprescindível, principalmente no que diz respeito às performances modernas da Antiguidade Clássica, que, à luz da teoria da Recepção da Performance, proposta por Hall (2010), necessitam de uma apurada investigação nos textos, nos depoimentos da audiência, nos materiais fotográficos e de divulgação, nos diálogos estabelecidos ao longo dos séculos e no resgate de signos e teorias de diferentes períodos, o que reforça a ideia de três, dos oito tópicos presentes na análise da professora de Oxford, quer sejam: mimese, memória e psique.

Por muitos anos, o que hoje se entende por performance do drama clássico pertencia aos estudos denominados Classical Tradition (Tradição Clássica), sendo só a partir da década de 60, do século XX, que estudiosos passaram a ocupar-se exclusivamente dos elementos de representação presentes no texto antigo e, por conseguinte, na execução enquanto atividade cênica. Nesse universo, Hall (2010, p. 13) descreve a "Recepção da performance" como uma teoria que une os estudos tanto da Performance quanto da Recepção em um sistema que possibilita a compreensão de todas as facetas na encenação moderna de um drama antigo, respeitando, inclusive, o estudo de partes em outros tempos ignoradas na análise de uma montagem. Assim sendo, os estudos de Recepção da Performance analisam oito importantes partes da representação moderna de tragédias clássicas: translation (tradução), body (corpo), mimesis (mimese), memory (memória), psyche (psique), contingency (contingência), temporal orientation (orientação temporal) e political potency (potência política).

drama mais antigo que temos às peças da memória modernista tardia, como How I Learned to Drive, de Paula Vogel, e Dora, de Hélène Cixous, em que o reconhecimento tardio, que Freud chamaria posteriormente de Nachträglichkeit (referindo-se ao pós-processamento de um trauma ou memória) se evidencia. 
Para a autora (HALL, 2010, p. 14), quando uma peça é analisada de acordo com esses elementos, sua performance é mais bem compreendida em todas as esferas. Obviamente, quando se trata de uma análise do drama antigo, algumas questões podem ser mais evidentes e necessárias, ou seja, exigem um maior cuidado e atenção na discussão, por exemplo na escolha tradutória; todavia, é interessante notar como esses elementos, de fato, resolvem por si só toda a análise necessária para o profundo entendimento de uma montagem clássica na atualidade. É notório, também, como, em menor ou maior instância, os tópicos dialogam entre si com sutis nuances, como é o caso de não ser possível descartar, por exemplo, um suporte mnemônico quando se analisa a potência política de um espetáculo que pressupõe um repertório anterior do espectador ao mesmo tempo em que oferecerá recursos para posteriores reflexões.

Dessa forma, partindo do modelo teórico de análise proposto por Hall (2010), o presente artigo, focado na questão pertinente ao universo mnemônico, pretende-se ater aos tópicos mimese, memória e psique, para discutir alguns passos das representações dramáticas do teatro antigo dentro do ambiente universitário da FCLAr (sigla que se refere à Faculdade de Ciências e Letras, da Unesp, localizada na cidade Araraquara, no interior do Estado de São Paulo), dando especial atenção às peças que obtiveram grande destaque por suas avaliações e documentação. Entende-se aqui como avaliação e documentação os registros que existem sobre essas apresentações, levando-se em conta arquivos fotográficos, filmagens, chamadas comerciais, pôsteres, livretos, resenhas e críticas.

Embora o teatro perdure através dos séculos como uma das grandes manifestações culturais do mundo ocidental, transformando-se constantemente, não é possível esquecer que ele foi engendrado em um momento muito particular da história da humanidade, ou seja, trata-se de uma arte que surge da confluência das ações do homem grego e suas manifestações políticas, sociais e religiosas. 
Quando Aristóteles, por exemplo, discorre sobre o teatro, ele não o conhecia mais, o que restava ao filósofo eram apenas os textos de uma forma artística que movimentou toda uma sociedade ao longo do século $\mathrm{V}$ a.C. De qualquer forma, as obras literárias permaneceram vivas e algumas resistiram ao longo do tempo. Nelas, por mais que o que nos é viável seja explorar os elementos performáticos impressos nos textos, é justamente a presença da forma escrita que permite, na atualidade, que encenações mantenham viva uma epifania artística análoga à vivenciada pelos helênicos.

É notório que, ao longo dos séculos, as performances do teatro antigo deram espaço a novos movimentos, novas perspectivas de encenação, novos temas e, por conseguinte, novas teorias. Todavia, vale enfatizar, também, que o teatro grego sempre foi memória presente em toda a história da literatura dramática. No caso do Brasil, que possui um histórico mais recente de encenações clássicas, foi depois da década de sessenta, do século XX, que surgiu esse resgate do teatro clássico.

Não é tarefa fácil delimitar os movimentos que fazem com que a tragédia ou a comédia sejam revisitadas, mas é fato que tal experiência está ligada a inúmeros fatores históricos que estejam acontecendo nos países que as revisitam. Sendo assim, por mais que um mito, no caso da tragédia, ou uma situação cotidiana da Atenas do século $\mathrm{V}$, para a comédia, dialoguem a princípio com uma população específica, os inúmeros dados constituintes das peças falam, primordialmente, sobre o ser humano, as relações sociais, os sentimentos, entre outros aspectos que impedem os textos clássicos de permanecerem cristalizados em um período específico da história do Ocidente.

Veículo de uma reflexão moral, social, política e cultural, o teatro ganhou força, no Brasil inclusive, no ambiente universitário. Na história do teatro nacional, por exemplo, a academia tornou-se, a partir do século XX, o lugar de disseminação das práticas dramáticas. De acordo com Azevedo (2000, p. 27), tratava-se de uma nova experiência em relação ao 
teatro:

\begin{abstract}
A maior parte do teatro acadêmico pode ser considerada como um teatro empenhado. Se seus enredos permanecem quase sempre no tradicional relato de encontros e desencontros amorosos, seu pano de fundo é essencialmente político e social; não político no sentido partidário do termo, mas no sentido da representação dos conflitos que estavam latentes na sociedade brasileira. O teatro deveria desempenhar uma função civilizatória. Deveria levar ao público os questionamentos e, se possível, as soluções para os problemas brasileiros.
\end{abstract}

Destarte, assim como o teatro engajado do início do século, ao qual se refere Azevedo, "deveria desempenhar uma função civilizatória”, o mesmo sentimento persiste, e é possível pensar que tampouco deixa de ser político o engajamento dos professores da Faculdade de Ciências e Letras de Araraquara, na segunda parte da década de 80 do século XX. A ideia de popularizar o teatro clássico entre alunos que não chegariam a ter contato com esse tipo de drama não deixa de ser parte de um engajamento políticosocial dos profissionais acadêmicos que, em certo momento, sentem a necessidade de transmitir para além do pequeno grupo de estudantes de grego ou latim para o qual lecionam a tradição teatral antiga.

Assim, no início da década de 80 , do século XX, o Giz-en-Scène começou a ser pensado, até que, em 1987, define-se o nome em referência à expressão francesa Mise-en-Scène, que gerou o interessante trocadilho. O nome, por fim, ficou definido como Grupo de Leituras Dramatizadas Giz-en-Scène. A presença, no nome, da expressão "leitura dramatizada" é um importante aspecto e diferencial do grupo. Com uma proposta inicial de leitura, aos poucos, foram surgindo novas necessidades e invenções estéticas que se uniram à postura performática completa, que extravasa a leitura experimental, própria dos atores em fase de decoração dos textos teatrais. 
Ao longo dos anos, muitos foram os alunos e professores que deram vida às personagens lidas pelo Giz-en-Scène e, mesmo com essa rotatividade, os leitores com maior experiência e outras participações transmitem com grande generosidade e auxiliam na estreia dos novos leitores. Esse aspecto garante ao grupo uma solidez dificilmente encontrada e que, amparada na seriedade dos professores que iniciaram o grupo e estão transmitindo o conhecimento, perdurará por muito tempo.

Quando surgem os estudos de Performance e Recepção, a principal preocupação dos estudiosos estava relacionada com a recordação posterior de uma representação cênica. Entre as questões que apareciam, estava a necessidade de documentar o resgate do universo clássico, e, ao mesmo tempo, confrontá-lo com a estética da modernidade. A esse respeito, por exemplo, Hall (2010, p. 12) lembra que uma análise de Ifigênia em Áulis, de Eurípides, à luz da experiência Protestante e Católica, tem muito a oferecer em diálogo com a narrativa da Antiguidade.

À vista do que foi dito até o momento, estudar a Recepção da Performance envolve mergulhar em um universo que vai desde a coleta de informações sobre a encenação até a leitura do texto dos diretores. Ademais, tal processo se demonstra tão complexo que, segundo Hall (2010, p. $13)$, atualmente se pode verificar que nunca dois especialistas apreendem a mesma visão sobre o espetáculo, e alguns elementos, de vivência pessoal ou intelectual, extrapolam o que é encenado, o que sugere, também, a identidade mnemônica do crítico, pois sua experiência ativa recordações e perpetua impressões que pertencem a uma esfera extremamente subjetiva.

O significado adotado para a palavra Performance remonta aos anos 60, do século XX. De acordo com Pavis (2008, p. 284), o termo representa muito mais do que apenas a encenação da ideia transmitida por um dramaturgo em sua obra, sendo o conjunto de elementos que compõem a peça teatral e as possibilidades inúmeras de se investigar esse processo, desde as unidades físicas até seus efeitos mais subjetivos, em uma arte que 
se realiza de forma híbrida e multifacetada.

Posto isto, o uso que o ator faz de seu próprio corpo diz muito sobre uma performance, da mesma forma que também sugere questões importantes de sua recepção. Está, portanto, o corpo ligado intimamente com a mimese do espetáculo. Se por um lado, o ator empresta seu corpo para a encenação e o espectador reconhece que se trata de uma representação, por outro, identificar o que é apresentado está psicologicamente ligado ao processo de rememoração com a experiência pessoal do espectador.

O processo de reconhecimento do espectador com a personagem apresentada é ponto importante dos estudos de Recepção da performance, principalmente porque é a partir da análise da recepção de uma obra que é possível perceber como, ao longo dos tempos, novas composições, peças inspiradas nas obras clássicas ou mesmo grupos sociais, todos estes, através de um processo mimético, puderam explorar suas próprias identidades.

$\mathrm{O}$ estudo dos processos miméticos é também uma forma de serem observados encadeamentos diacrônicos e sincrônicos no que diz respeito à própria recepção crítica de uma representação teatral. Para Hall (2010, p. 18), muitos atores passam a ser conhecidos pelos personagens desempenhados em um espetáculo e possibilitam comparações com outras apresentações, anteriores e posteriores. No caso do Giz-en-Scène, por exemplo, muitos são os professores e alunos que, ao longo dos últimos trinta anos, passaram pela trupe. No entanto, alguns professores, ainda atuantes na universidade, e outros pesquisadores, os quais eventualmente realizam participações no grupo, tornaram certas participações memoráveis. Um desses personagens é o escravo Gêtas, da peça Misantropo, de Menandro, interpretado por João Batista Toledo Prado, professor do curso de Latim. Em outras ocasiões, mesmo interpretado por outros atores, alguns trejeitos e atitudes, próprios do estilo de Prado de interpretar, foram mantidos, aspecto que rememorava o sucesso das antigas representações, mas, por outro lado, dava novos traços e fôlego ao personagem. 
Tal atitude, assim, condiz com o que Hall (2010, p. 19) diz a respeito de personagens aclamados. Nesse sentido, a mimese é um momento de repensar movimentos psicológicos ativados em outros espetáculos. Assim, um ator que interpretará um personagem já aclamado tende, naturalmente, à emulação ${ }^{6}$, o que torna cada montagem diferente uma da outra.

Além disso, cenários, figurinos e certos objetos também refletem uma perspectiva mimética no público, como é o caso de Jean-Claude, nome carinhoso dado ao boneco que simula um dos crucificados na Matrona de Éfeso e Arnauld, l'agneau, a ovelha mascote do grupo. Quando tais signos cênicos são utilizados em outras apresentações ou fazem "participações especiais", o público automaticamente os relaciona às outras montagens.

Acerca da presença da memória no universo dramático, Favorini (2009, p. 86) é assertivo ao discorrer sobre uma lógica muito mais acentuada de rememoração nos tempos atuais:

Theatre of the modern era is theatre of memory. What a standard textbook history of modern theatre terms a "century of innovation" is also a century of memoration, in which memory becomes a persistent and intrusive subject of the drama, as well as an object whose contours are shaped by the many arts of theatre. Though the differential "isms" constituent of modernism and postmodernism have been endlessly anatomized, the perdurance of memory on this changing scene has gone largely unnoticed, perhaps because modernism is so commonly considered as a break with the past - an estimate currently undergoing reconsideration. Coincidental with the rise and maturity of psychology as a modern life science, dramatists brought memory in a major role to the field of play; aptly enough, at just about the same time, modern thinkers about memory discovered the theatrical

6 O termo aqui é usado em seu sentido mais primitivo possível. Para Cícero (Tusc. IV.8), trata-se de uma forma de o autor, ao retomar obras célebres, homenagear seu predecessor, obviamente inserindo seu próprio estilo e pensamento, mas nunca deixando de lado a essência visitada na obra de partida. 
metaphor as explanatory model. ${ }^{7}$

Assim, é justamente pensando no teatro como veículo condutor de ideias que envolvem processos externos e internos, no que diz respeito às reflexões do próprio indivíduo, a memória, segundo Hall (2010, p. 22), é o reforço da permanência posterior da imagem criada pelo espetáculo, o impacto e suas repercussões na audiência. Uma presença memorável no grupo é a de Fernando Brandão dos Santos, professor de Língua e Literatura grega e membro efetivo da trupe, que, em todas as apresentações de Nuvens, de Aristófanes, interpreta o filósofo Sócrates. O cômico da situação, para além da atuação do professor, encontra-se no fato de Brandão dos Santos ter baixa estatura e entrar em cena, em sua primeira aparição, no alto das nuvens, ou seja, muito acima do palco, o que torna o momento antológico, principalmente pelo caráter amistoso do acadêmico, conhecido entre os alunos da universidade.

Essa identificação com o público, por outro lado, também pode extrapolar os níveis miméticos e mnemônicos, levando o espectador a uma experiência psíquica. Sendo assim, a psique, aspecto também abordado por Hall (2010, p. 23), refere-se ao universo dos gatilhos que uma representação, em diálogo com a Antiguidade, pode proporcionar com relação a uma experiência extremamente individual. Por conseguinte, não são poucos os artifícios utilizados pelo Giz-en-Scène que despertam no espectador. Um exemplo sobre o uso do cenário em favor da encenação está relacionado com a montagem de Medeia, de Eurípides, em que o espectador é

$7 \quad$ O teatro da era moderna é o teatro da memória. O que uma história-padrão do teatro moderno chama de "século de inovação" também é um século de memorização, em que a memória se torna um assunto persistente e intrusivo do drama, bem como um objeto cujos contornos são moldados pelas muitas artes do teatro. Embora os diferentes "ismos" constituintes do Modernismo e do Pós-Modernismo tenham sido infinitamente anatomizados, a perda da memória nessa cena em mudança passou despercebida em grande parte, talvez porque o Modernismo seja tão comumente considerado como uma ruptura com o passado - uma avaliação atualmente sendo reconsiderada. Coincidentemente, com o surgimento e maturidade da psicologia como ciência da vida moderna, os dramaturgos trouxeram a memória para um papel de destaque na peça; apropriadamente, quase ao mesmo tempo, os pensadores modernos, a respeito da memória, descobriram a metáfora teatral como modelo explicativo. 
levado a resgatar em seu íntimo informações sobre sua vivência e a organização sociocultural do mundo. Embora o grupo tente explorar com certa fidelidade as vestes gregas, romanas ou indianas, dependendo do contexto, também não deixa de buscar a inovação em diversos aspectos. No caso da encenação de Medeia, o grupo resolveu fazer uso de jornais para confeccionar o fundo cênico, criando, dessa forma, um conglomerado de informações e imagens que, a princípio, tinham como intenção apenas criar um ambiente sensacionalista com notícias trágicas e sanguinolentas, mas que se tornou um verdadeiro choque visual, explicitando constantemente aos espectadores que aquela conjuntura vivida pela heroína com o marido e os filhos é reflexo de uma situação que pode, ainda hoje, estar perfeitamente estampando as capas dos jornais. Ademais, em meio aos discursos em voga, principalmente no que concerne às teorias sobre o Feminismo e aos índices de feminicídio no Brasil, o impacto individual é sentido até mesmo durante a própria apresentação, o que é reforçado, posteriormente, pelo exercício do resgate mnemônico.

Nota-se, portanto, que mimese, memória e psique dialogam entre si, mesmo que elas dependam de gatilhos diferentes. Em um vídeo, disponibilizado na plataforma YouTube ${ }^{8}$, há uma cena memorável da comédia Um deus dormiu lá em casa, de Guilherme de Figueiredo, que exemplifica melhor essa questão. Quando a entrada de Anfitrião é anunciada pelo arauto, que o compara a Aquiles, José Dejalma Dezotti, professor aposentado do curso de Latim, ao entrar em cena, de forma extremamente performática, além da aparência pouco heroica, faz referência a um gestual muito comum na atualidade, próprio de artistas e personalidades quando são aclamados pelo público. Tal fato contagiou os espectadores e gerou a manifestação da audiência. Aqui, a cena só se torna cômica justamen-

7 GIZ-EN-SCÈNE. Um deus dormiu lá em casa: Parte I. Disponível em: https://youtu.be/03XzRSMbIqQ. Acesso em: 01 jun. 2020. 
te porque ela depende dos três processos propostos na recepção da performance; primeiramente, a ideia mimética gerada pelo gestual próprio das celebridades, conflitante com a postura de um guerreiro; em segundo lugar, a memória da figura do professor, descaracterizado de sua postura hierárquica da sala de aula, aspecto que pode, inclusive, ser rememorado posteriormente; e, por fim, o estímulo psíquico quanto aos elementos de composição da cena, que envolve o herói em situação pós-bélica, a chegada em casa, o momento espaço-temporal da ação e, principalmente, o elo com a cultura midiática atual.

Sendo assim, é possível perceber que a memória permanece como a conexão dos processos miméticos e psíquicos, evocando a permanência de um resgate que, no caso do teatro clássico, ganha uma nova leitura. Ao ponderar sobre o drama grego, Vernant e Vidal-Naquet (1999, p. 233) pontuam que, na tragédia, "é preciso que a cidade ao mesmo tempo se reconheça e se questione". Embora os estudiosos estivessem preocupados com outro contexto, relacionado com o impacto social das produções dramáticas daquele período, é preciso ressaltar que tal propósito da tragédia se estende à própria arte teatral que, obrigatoriamente, ao fazer, ainda hoje, o homem se questionar sobre o "ser" e o "não- ser" (TORRANO, 1995, p. 22), transporta ciclicamente o drama à grande progenitora: Memória.

\section{Referências}

AZEVEDO, Elizabeth Ribeiro. Um palco sob as arcadas: o teatro dos estudantes de Direito do Largo de São Francisco, em São Paulo, no século XIX. São Paulo: Annablume; Fapesp, 2000.

CICERO. M. Tullius Cicero: Tusculanae Disputationes. Ed. M. Pohlenz. Leipzig: Teubner, 1918.

EURIPIDES. Bakkhai. Tradução de Reginald Gibbons. Introdução de Charles Segal. New York: Oxford University Press, 2001. 
FAVORINI, Attilio. Memory in play: from Aeschylus to Sam Shepard. New York: Palgrave MacMillan, 2009.

GIZ-EN-SCÈNE. Um deus dormiu lá em casa: Parte I. São Paulo, [200-?], 1 vídeo (10 min). Disponível em: https://youtu.be/03XzRSMbIqQ. Acesso em: 01 jun. 2020.

UM MANIFESTO 2.0 do bibliotecário. Mash up por laura Cohen. Tradução: Maria José Vicentini Jorente. [S. 1.: s. n.], 2007. 1 vídeo (4 min). Disponível em: http://youtube.com/watch?vYj1p0A8DMrE. Acesso em: 12 maio 2010.

HALL, Edith.; HARROP, Stephe. (org.) Theorising Performance: Greek Drama, Cultural History and Critical Practice. Great Britain: Duckworth, 2010.

HALL, Edith. Towards a Theory of Performance Reception. In: HALL, Edith.; HARROP, Stephe. (org.) Theorising Performance: Greek Drama, Cultural History and Critical Practice. Great Britain: Duckworth, 2010, p. $10-28$.

HESIOD. Theogony and Work and Days. Tradução de Catherine Schlegel e Henry Weinfield. Michigan: Michigan University Press, 2006.

HESÍODO. Teogonia. A origem dos deuses. Trad. Jaa Torrano. São Paulo: Iluminuras, 1995.

LORAUX, Nicole. The mourning voice: an essay on Greek tragedy. Trad. Elizabeth Trapnell Rawlings. Nova York: Cornell University Press, 2002.

PAVIS, Patrice. Dicionário de teatro. 3. ed. Tradução de J. Guinsburg e Maria Lúcia Pereira. São Paulo: Perspectiva, 2008.

VERNANT, Jean-Pierre; VIDAL-NAQUET, Pierre. Mito e tragédia na Grécia antiga. Tradução de J. Guinsburg. São Paulo: Perspectiva, 1999. 
DOI: http://dx.doi.org/10.22409/cadletrasuff.2019n59a768

Artigo recebido em: 31/10/2019

Aprovado em: 12/06/2020 